\title{
Synthesis of BMS-741672
}
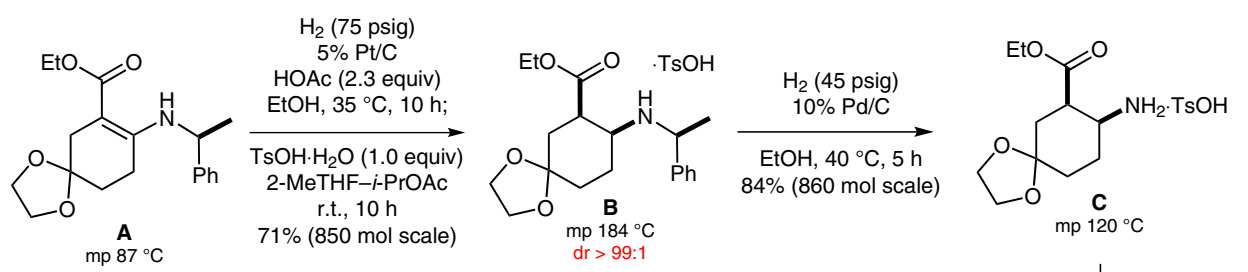

$\mathbf{A}$
$\mathrm{mp} 87^{\circ} \mathrm{C}$

r.t., $10 \mathrm{~h}$
$71 \%(850 \mathrm{~mol}$ scale $)$

$\mathrm{dr}>99: 1$<smiles>CCOC(=O)C1CCC2(CC1C(=O)OCC)OCCO2</smiles>

L- $\mathrm{N}-\mathrm{Cbz}-\mathrm{Met}-\mathrm{OH}$ (1.05 equiv)<smiles>CCOC(=O)C1CC2(CCC1N1CC[C@H](NC(=O)OCc3ccccc3)C1=O)OCCO2</smiles>

1. $\mathrm{Mel}$ (15.5 equiv) EtOAc, r.t., $20 \mathrm{~h}$

2. $\mathrm{Cs}_{2} \mathrm{CO}_{3}$ (1.1 equiv) DMSO, $21^{\circ} \mathrm{C}$

$170 \mathrm{~mol}$ scale

Freidinger lactamization

mp $110^{\circ} \mathrm{C}$

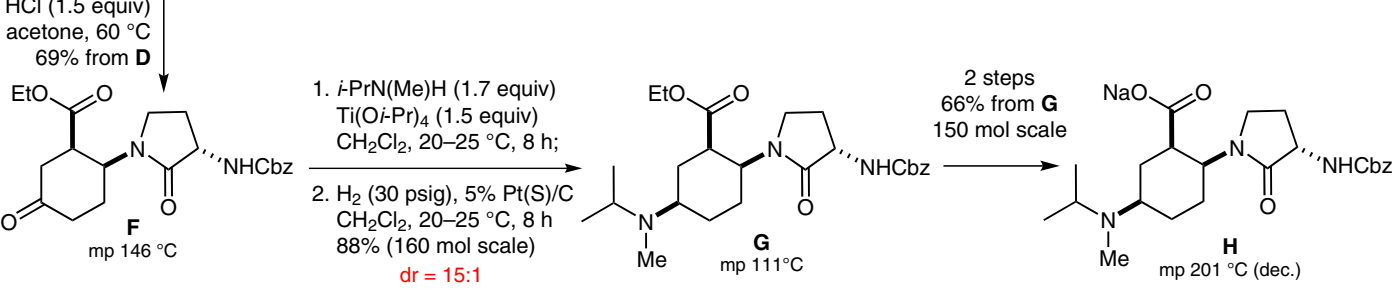

$\mathrm{dr}=15: 1$

(1.0 equiv)

PEA (2.2 equiv)

$\mathrm{MeCN}$, r.t., $3 \mathrm{~h}$

$96 \%(340 \mathrm{~mol}$ scale)
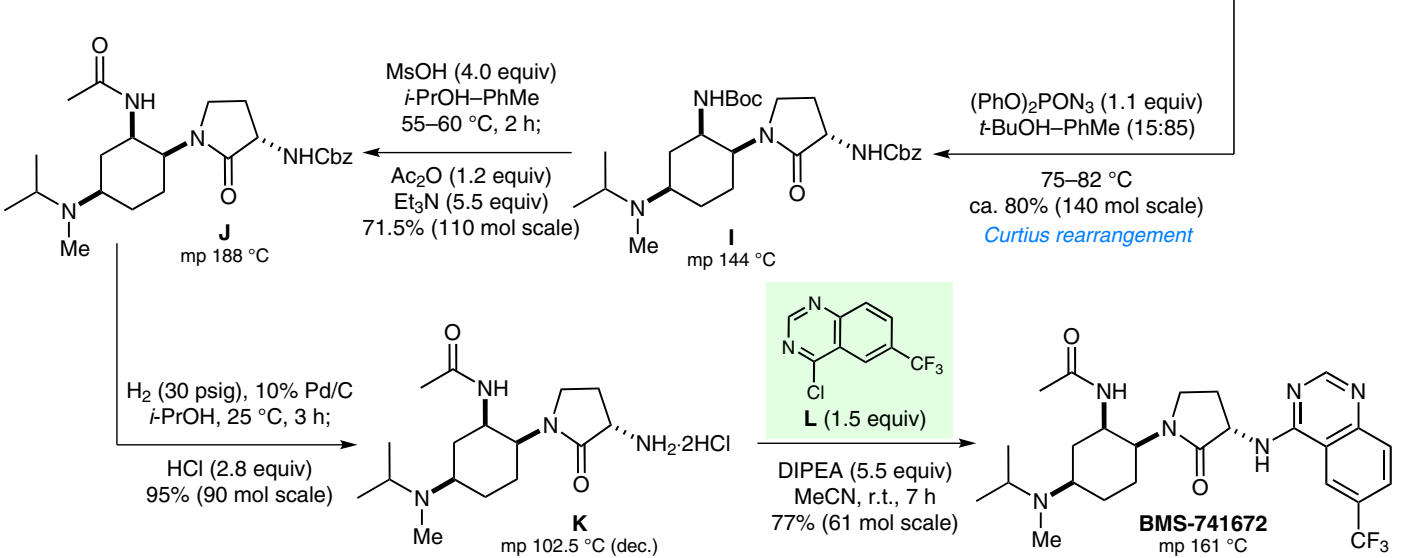

Synthesis of Natural

Products and

Potential Drugs

Key words

\section{BMS-741672}

CCR2 antagonist

diastereoselective hydrogenation

reductive amination

\section{Curtius}

rearrangement

Freidinger

lactamization

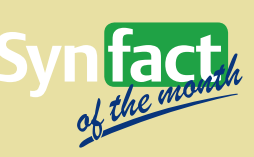

Significance: BMS-741672 is a chemotactic chemokine receptor 2 (CCR2) antagonist that is of interest for the treatment of inflammatory, cardiovascular, and metabolic diseases. A salient feature of the synthesis depicted is the construction of the all-cis 1,2,4-triaminocyclohexane core. This route delivered $50 \mathrm{~kg}$ of the target in 12 steps and in $9 \%$ overall yield.
Comment: A platinum-catalyzed reduction of $\beta$ enaminoester $\mathbf{A}$ using $(S)$ - $\alpha$-methylbenzylamine as a low-cost chiral template and reductive amination of the 3,4-cis-disubstituted cyclohexanone $\mathbf{F}$ with a secondary amine on a sulfided platinum catalyst established the stereochemistry in the trisubstituted cyclohexane $\mathbf{G}$.

SYNFACTS Contributors: Philip Kocienski

Synfacts 2017, 13(02), 0119 Published online: 18.01.2017

Dol: 10.1055/s-0036-1589893; Reg-No.: K07816SF 